\title{
Effects of tactile stimulation on the initiation and maintenance of the following response in Japanese quail (Coturnix coturnix japonica)
}

\author{
MAUREEN CLEMENTS and JON LIEN \\ Animal Behavior Laboratory, Memorial University of Newfoundland, St. John's, Newfoundland, Canada
}

\begin{abstract}
Effects of tactile contact with an imprinting stimulus object on the initiation and maintenance of the following response in neonatal Japanese quail, Coturnix coturnix japonica, were examined. Tactile contact with an imprinting stimulus object was permitted during a preexposure period and/or during a following test. Results indicated that following was stronger when tactile contact was permitted during either the preexposure or test periods than when such contact was not given. Following occurred sooner when contact was permitted during the preexposure period than during following only, or when no contact was permitted. The greatest strength of following occurred when tactile stimulation was permitted during both preexposure and testing periods. It was concluded that the results support the hypothesis that tactile stimulation can facilitate both the initiation and maintenance of following behavior, and this is interpreted as being consistent with Schneirla's (1965) theory.
\end{abstract}

Schneirla (1965) has suggested that the following response of young nidifugous birds has antecedents in embryo behavior, particularly in early movements of the head. He indicated that head movements initially come under control of low intensity, proximal stimuli, such as tactile stimuli, when the head of the embryo is raised and comes into contact with soft contractile tissues. Such low intensity stimulation arouses "A-processes" and repetition of this sequence results in the establishment of an "approach fixation" to each stimulation. According to Schneirla, it is this local approach response, established in the embryo, which gradually develops into the following response of the neonate, i.e., the head of the neonate is advanced toward a stimulus source and as that source moves away, the neonate must emit locomotor responses to maintain the stimulus configuration.

Apart from naturalistic observations on tactile contact between chick and hen during brooding, very few investigators have reported on effects of tactile contact on the development of such stimulus preferences. Smith (1962) allowed chicks contact with the surface of a board as approach to a visual stimulus occurred, but found no effect of this contact on later preferences for the visual stimulus with which it was paired. Smith and Bird (1963) allowed contact with a hard white ball after subjects made an approach response to it. However, no effect of this contact over several days was noted on approach behaviors. Collins (1965) allowed chicks contact with a model of a hen, both during following at $48 \mathrm{~h}$ of age and during testing

Financial support for this work was received from the President's Research Fund, Memorial Univerdity of Newfoundland. The authors are grateful to Cathy Noseworthy and John Evans for their critical comments on the manucaript and to Ms. Y vonne Mulcahy for her secretarial help.

The first author is now at the Department of Psycholosy. College of Cape Breton, Sydney, Nova Scotia, Cannda. five days later, but found no facilitating effect of contact on the following response. Taylor and Sluckin (1964), however, investigating stationary tactile imprinting, found that chicks showed significant contact preferences for a soft, rough object to a firm smooth one.

In contrast to the results obtained in the above studies, Maier (in Maier \& Maier, 1970) noted that contact appeared to be important in maintaining following preferences as chicks lost their responsiveness to the hen when brooding by her was inhibited. Also, Hess (1959) observed that young chicks, even prior to efficient locomotion, attempted to crawl under cover of a stimulus object. Additionally, tactile stimulation has been reported to elicit some neonatal following, as indicated by Collias (1952) and Obda (1962), who noted that naive chicks rarely followed or approached another chick until physical contact with it had occurred. Others, such as Salzen (1970), note that nestling, which includes pushing the head under the hen, typically occurs prior to following. Several investigators, such as Bjärvall (1968), have presented data which clearly indicates that nest exodus, involving following by the young, does not occur until many hours after the sensitive period typically observed for imprinting in laboratory studies. Such an extensive period of brooding contact during the sensitive period for imprinting would seem to indicate that under natural circumstances tactile contact may well be important in later following.

In a previous experiment evaluating the effects of contact with an imprinting stimulus on initiation of following, Clements (Note 1) found that following was stronger when Japanese quail chicks were allowed previous tactile contact with the imprinting stimulus object. The present study examines the role of tactile 
Table 1

Means and Standard Deviations of the Following Response

\begin{tabular}{clrrrr}
\hline $\begin{array}{c}\text { Height (cm) } \\
\text { of Stimulus } \\
\begin{array}{c}\text { Object Dur- } \\
\text { ing Pre- } \\
\text { exposure }\end{array}\end{array}$ & \multicolumn{4}{c}{$\begin{array}{c}\text { Height (cm) of Stimulus } \\
\text { Object During Following }\end{array}$} \\
\cline { 2 - 6 } & & 1.3 & 5.1 & 6.4 & $\begin{array}{c}\text { Total } \\
\text { Mean }\end{array}$ \\
\hline \multirow{2}{*}{1.3} & Mean & 64.95 & 41.90 & 44.65 & 50.5 \\
& SD & 20.17 & 18.58 & 15.64 & \\
5.1 & Mean & 38.45 & 34.25 & 33.35 & 35.35 \\
& SD & 17.61 & 15.00 & 14.43 & \\
6.4 & Mean & 45.1 & 35.00 & 38.80 & 39.63 \\
Total & SD & 20.55 & 16.59 & 17.42 & \\
Mean & & 49.5 & 37.05 & 38.93 & \\
\hline
\end{tabular}

stimulation in both the initiation and maintenance of the following response. Three preexposure periods were used, one which forced tactile contact with the stimulus object and two which exposed the subject to the imprinting stimulus visually but did not allow tactile contact. Three similar conditions were used during the following test. If tactile stimulation functioned to initiate following, then stimulation during the preexposure period should result in stronger following. If, however, maintenance of the response is its function, then tactile stimulation during following should result in strong following. If both functions are important and additive, then tactile stimulation during both preexposure and following should lead to stronger following than when it is given during only one of these periods. Additionally, tactile stimulation during either period should lead to stronger following than when there is no tactile stimulation.

\section{METHODS}

Subjects. One hundred and eighty Japanese quail, Coturnix coturix japonica, from the breeding flock at the Animal Behavior Laboratory, M.U.N., were incubated in nine batches. When hatched chicks were randomly assigned to one of nine conditions and placed in visual isolation until testing at 4 to $8 \mathrm{~h}$ posthatch. Pretest investigations indicated that younger chicks were not strong enough to maintain sustained following and a high proportion of older neonates actively avoided the imprinting stimuli utilized.

Apparatus. Visual isolation chambers consisted of 15-cu-cm opaque plexiglas compartments heated by infrared lamps. A standard gray $200-\mathrm{cm}$ dia imprinting apparatus was used. The floor was marked with black lines at $10 \mathrm{deg}$ angles. The apparatus had double walls, $35 \mathrm{~cm}$ high, that made a circular track $50 \mathrm{~cm}$ long around its outer edge. Plastic insect screening was placed on the floor to provide traction. The entire track could be viewed by a combination of mirrors located over the apparatus and by direct observation. A centrally located infrared lamp provided heating and lighting. This lamp maintained the temperature evenly around the track at between $32^{\circ}-36^{\circ} \mathrm{C}$.

The visual and tactile stimulus object was a $14-\mathrm{cm}$ dia beige wool ball made in the form of a tight "pom-pom." This was suspended from an arm attached to a centrally located $1 / 2$ RPM motor programmed by cycle timer, which caused the object to rotate around the track at a speed of $3.9 \mathrm{~cm} / \mathrm{sec}$. A tape recording of the experimenter whistling was played through a speaker attached to the rotating arm. Pretest investigations indicated that this combination of visual and auditory stimuli elicited optimal following in Japanese quail (Clements, Note 1). A vire mesh cylinder, $18 \mathrm{~cm}$ in dia, was placed around the stimulus object to contain the chick for the preexposure period.

Procedure. Three stimulus object heights were used: $1.3 \mathrm{~cm}$ from the floor to the lower surface, which allowed the chick to contact it; or $5.1 \mathrm{~cm}$ and $6.4 \mathrm{~cm}$, which did not allow contact. In pretests, Japanese quail chicks were found to typically maintain contact with the stimulus object at the $1.3 \mathrm{~cm}$ height but could not reach it at the 5.1 and $6.4 \mathrm{~cm}$ heights. Two noncontact heights were used to control for the differential effect that vertical visual angle might have on following. A pilot study indicated that there was no significant difference between the two noncontact heights in eliciting following. The trends, however, were for the $6.4 \mathrm{~cm}$ height to lead to better following that the $5.1 \mathrm{~cm}$ height.

The three stimulus heights were varied in all possible combinations during preexposure and testing and incorporated into a $3 \times 3$ factorial design with 20 subjects per cell. The preexposure period was three min, during which time chicks were confined inside the wire cylinder with the visual stimulus object set at one of the three heights. Auditory stimulation was continuous during both preexposure and testing. There was a $10-\sec$ break between preexposure and testing to allow for the removal of the wire circle and adjustment of the stimulus object height where necessary. Testing was then continued for $12 \mathrm{~min}$ in the imprinting apparatus. In this time the stimulus object made four revolutions of the track, moving for $10 \mathrm{sec}$ and remaining stationary for five sec. Dependent measures were the total amount of following response, and total activity. Following was measured as the number of lines on the floor of the apparatus crossed by the stimulus object while the chick was within the area four lines behind and two lines in front of the stimulus object. This measure, which is a similar one to time spent near the stimulus object, was felt to be more suited to the very active Cotumix chicks than measuring their own activity, which would inevitably include a considerable degree of random activity. Since the criterion area included 6 out of the total 36 lines of the apparatus, a chick's activity, if totally unrelated to the stimulus object, would take it into the criterion area for $1 / 6$ of the time on a chance basis. Thus a chance following score would be 24 , or $1 / 6$ of the total lines crossed by the stimulus object during testing. Total activity was measured as the total number of lines on the floor of the apparatus crossed by the chick during the testing period. This latter measure was recorded to insure that general activity was equivalent across all groups.

\section{RESULTS}

Means and standard deviations of the following response are presented in Table 1 . As this table shows, the mean following scores in all the groups are above the chance score of 24 , indicating that the chicks in all the groups followed to some degree. Single sample $t$ tests indicated that the degree of following in all groups was significantly above the chance level ( $p<.02$ in all cases). Analysis of variance indicated that the main effects of both variables, stimulus height during preexposure and during following, were significant $(F=12.12, p<.01$ and $F=8.72, p<.01$, respectively). Multiple comparisons on the main effects, using the Neuman-Keuls procedure, indicated that the effect of 
the lowest stimulus height was to elicit significantly greater following $(\mathrm{p}<.01)$ than either the $5.1 \mathrm{~cm}$ or $6.4 \mathrm{~cm}$ heights, which did not differ from each other.

Means and standard deviations of the length of first following response are shown in Table 2. Analysis of variance indicated that the main effect of stimulus height during preexposure was significant $(F=7.16$, $\mathrm{p}<.01$ ) and the Neuman-Keuls test indicated that the $1.3 \mathrm{~cm}$ stimulus height elicited a significantly longer first following response than did either of the other heights, which were not different from each other. Neither the main effect of stimulus height during following nor the interaction was significant $(F=2.1, p>.05, F>1)$.

Means and standard deviations of total activity are shown in Table 3. An $F_{\max }$ test on these data was not significant. Analysis of variance on these data indicated that neither the interaction nor the main effects were significant. A Spearman's rank correlation between the following means and the total activity means for each condition showed a small negative relationship between following and total activity (rho $=-.133$ ) but was not significant.

\section{DISCUSSION}

Results of the present study are consistent with the prediction that tactile stimulation can facilitate both the initiation and maintenance of the following response in Japanese quail chicks.

The initial importance of tactile stimulation on following is indicated by the finding that contact during the preexposure period led to stronger following than when contact was not allowed during this period. The longer first following response emitted by the chicks in the conditions that received contact during the preexposure period also indicated the importance of this stimulation. This latter measure suggests that an attempt is made by the neonate to maintain, by locomotor following, the tactile stimulation it received during preexposure.

The stronger following behavior emitted by the

Table 2

Means and Standard Deviations of Length of First Following Response

\begin{tabular}{clllll}
\hline $\begin{array}{c}\text { Height }(\mathrm{cm}) \\
\text { of Stimulus } \\
\text { Object Dur- } \\
\text { ing Pre- }\end{array}$ & \multicolumn{4}{c}{$\begin{array}{c}\text { Height (cm) of Stimulus } \\
\text { Object During Following }\end{array}$} \\
\cline { 2 - 6 } exposure & Mean & 7.45 & 5.7 & 5.05 & $\begin{array}{l}\text { Total } \\
\text { Mean }\end{array}$ \\
\hline \multirow{2}{*}{1.3} & SD & 7.05 & 4.62 & 2.8 & 6.07 \\
& Mean & 3.5 & 2.95 & 3.95 & \\
5.1 & SD & 2.06 & 1.6 & 3.69 & 3.47 \\
& Mean & 5.25 & 3.45 & 3.7 & \\
6.4 & SD & 3.8 & 4.07 & 2.66 & 4.13 \\
Total & & 5.40 & 4.03 & 4.23 & \\
Mean & & & & & \\
\hline
\end{tabular}

Table 3

Means and Standard Devintions of Total Activity Scores

\begin{tabular}{|c|c|c|c|c|}
\hline \multirow{2}{*}{$\begin{array}{c}\text { Height (cm) } \\
\text { of Stimulus } \\
\text { Object Dur- } \\
\text { ing Pre- } \\
\text { exposure }\end{array}$} & & \multicolumn{3}{|c|}{$\begin{array}{l}\text { Height }(\mathrm{cm}) \text { of Stimulus } \\
\text { Object During Following }\end{array}$} \\
\hline & & 1.3 & 5.1 & 6.4 \\
\hline 1.3 & $\begin{array}{l}\text { Mean } \\
\text { SD }\end{array}$ & $\begin{array}{l}211.75 \\
130.12\end{array}$ & $\begin{array}{l}175.25 \\
101.99\end{array}$ & $\begin{array}{l}199.95 \\
100.48\end{array}$ \\
\hline 5.1 & $\begin{array}{l}\text { Mean } \\
\text { SD }\end{array}$ & $\begin{array}{l}214.00 \\
157.64\end{array}$ & $\begin{array}{l}183.05 \\
124.62\end{array}$ & $\begin{array}{l}196.15 \\
124.62\end{array}$ \\
\hline 6.4 & $\begin{array}{l}\text { Mean } \\
\text { SD }\end{array}$ & $\begin{array}{r}161.00 \\
94.49\end{array}$ & $\begin{array}{l}268.75 \\
163.89\end{array}$ & $\begin{array}{l}206.6 \\
103.80\end{array}$ \\
\hline
\end{tabular}

groups that were allowed to contact the imprinting stimulus during following indicates the importance of tactile stimulation in maintaining following behavior. In such instances this would appear to be a function of the reinforcing effect of tactile stimulation on following. That both initiation and maintenance of the following response by tactile stimulation are individually important is indicated by the stronger following emitted by the chicks which were able to contact the stimulus object during both following and preexposure.

An alternate way to that of Schneirla's hypothesis in which tactile stimulation might facilitate following is that contact with the stimulus object could increase arousal in the chicks. In this case it would be expected that an increase in arousal would also result in an increase in general activity level. There was, however, no significant difference in activity level between the groups and the trends of this measure were not related in any way to the contact variable. It would seem unlikely, therefore, that the increase in following in the contact groups was a function of increase in arousal occasioned by contact with the stimulus object.

One possible reason for the difference in results between this study and previous investigations of tactile effects on following is the rigidity of stimulus objects which previous investigators used. Another possible reason for the lack of observed effect of tactile contact in these earlier studies may be their use of relatively older chicks, which have already made the transition from proximal to distal stimulus control of approach behavior. In view, however, of the suggestion by Schneirla (1965) and Salzen (1970) that following behavior will wane without contact reinforcement, the effect of tactile stimulation on the following response of older chicks should be investigated. Still another possible basis for the discrepancy between the findings in this experiment and previous ones may be the species used. In pilot work (Clements, Note 1), Japanese quail chicks were found to perform differently from domestic chickens in the testing situation in that they actively avoided "conspicuous stimuli" which domestic chickens readily followed. Additionally, Japanese quail were ty pically more "contact oriented" than young domestic chickens. 


\section{REFERENCE NOTE}

Clements, M. Studies on the role of tactile stimulation in the early behavior development of several species of birds. MA Thesis, Memorial University of Newfoundland, 1971.

\section{REFERENCES}

Bjarvall. A. The critical period and the interval between hatching exodus in Mallard Duckling. Behavior, 28, 141-148. Collins, N. E. The development of social behavior in birds. Auk, 1952, 127-156.

Collins, T. B. Strength of the following response of the chick in relation to degree of 'parent' contact. Journal of Comparative and Physiological Psychology, 1965, 60, 192-195.

Hess, E. H. The relationship between imprinting and motivation. In $M$. $R$. Jones (Ed.), Current theory and research on motivation. Lincoln: University of Nebraska Press, 1959, Pp. 44-77.

Maier, R. A., \& Maier, B. A. Compartive animal behavior. Belmont, Calif.: Wadsworth, 1970.
Obda, K. Studies in socialization of white leghorn chicks. (I) Behavior of day old chicks at their first paired meeting. (Abstract) Annals of Animal Psychology (Tokyo), 1962, 12, 113-114.

Salzen, E. A. Imprinting and environmental learning. In $L$. $R$. Aronson \& E. Tobach (Eds.), A development and evolution of behavior. San Francisco: W. H. Freeman, 1970. Pp. 168-178.

Schneirla, T. C. Aspects of stimulation and organization in approach/withdrawal processes underlying vertebrate behavioral development. In D. S. Lehrman, R. A. Hind, \& E. Shaw (Eds.), Advances in the study of behavior. New York: Acad emic Press, 1965. Pp. 2-74.

Smith, F. V. Perceptual aspects of imprinting. Symposium of the Zoological Society of London, 1962, 8, 171-191.

Smith, F. V., \& Bird, M. W. Relative attraction for the domestic chick of combinations of stimuli in different sensory modalities. Animal Behavior, 1963, 11, 300-305.

Taylor, K. F. \& Sluckin, W. An experiment in tactile imprinting. (Abstract) Bulletin of the British Psychological Society, 1964, 17 (54), $10 \mathrm{a}$.

(Received March 25, 1974.

Revision accepted March 25, 1975.) 